\title{
“APESAR DE TUDO NÓS ESTAMOS AQUI PRA FAZER A DIFERENÇA”: GÊNERO, SEXUALIDADE E MOVIMENTAÇÃO ESTUDANTIL
}

Neilton dos Reis ${ }^{\mathrm{i}}$

\section{Resumo}

Neste artigo, apresento reflexões inseridas no campo do gênero e da sexualidade estabelecendo uma relação com as movimentações de estudantes secundaristas. Destaco essas movimentações como espaços privilegiados para a socialização e para a (re)construção de sentidos, identidade e saberes sobre diferença e diversidade. Parto de narrativas produzidas por jovens estudantes do Ensino Médio do estado do Rio de Janeiro em uma entrevista e em uma roda de conversa realizada em uma escola pública ocupada por estudantes no mesmo estado. Proponho pensar a construção realizada no espaço escolar e nesses movimentos acerca dos saberes sobre identidades, diferenças e realidades discentes, debatendo uma ação questionadora dos posicionamentos assumidos.

Palavras-chave: diferença; gênero; sexualidade; movimento estudantil; educação.

\section{Resumen}

En este artículo presentamos reflexiones insertadas en los estudios de género y la sexualidad que establecen una relación con el activismo de los jóvenes estudiantes. Destaco estos activismos como espacios privilegiados para la socialización y para la (re)construcción de sentido, identidad y conocimiento acerca de la diferencia y la diversidad. Comience con las narrativas producidas por jóvenes estudiantes o graduados de la escuela secundaria en el estado de Río de Janeiro con identidades de género sexual en una entrevista y en una rueda de conversación que tuvo lugar en una de las escuelas públicas ocupadas por los estudiantes en el estado. Propongo pensar la construcción lleva a cabo en el entorno escolar y el activismo estudiantil sobre el conocimiento de los identidades, diferencias y realidades de los estudiantes, debatiendo un cuestionamiento de las colocaciones de acción emprendida.

Palabras clave: la diferencia; género; la sexualidad; activismo estudiantil; la educación.

\section{Introdução}

Esse texto é fruto de discussões e atravessamentos iniciados no âmbito de uma pesquisa que pensou a diversidade de gêneros e sua relação com o ensino de Biologia e, mais tarde, 
experienciadas na produção da roda de conversa Gênero, sexualidade e movimentação estudantil. Objetivo, aqui, trazer algumas narrativas produzidas nesses dois momentos que me ajudam a pensar o saber discente sobre gênero e sexualidade construído dentro das movimentações estudantis no ambiente escolar, bem como algumas relações que se estabelecem dentro dessas movimentações. Trago, ainda, alguns apontamentos e potencialidades da própria movimentação estudantil secundarista, tanto para a escola quanto para o campo do gênero e sexualidade.

A pesquisa construiu-se em função de um trabalho de conclusão do curso de licenciatura em Ciências Biológicas da Universidade Federal Rural do Rio de Janeiro (DOS REIS, 2015) e teve como principal objetivo, pensar os sujeitos e as práticas pedagógicas implementadas por professoras e professores de Biologia do Ensino Médio do estado do Rio de Janeiro nas temáticas em gênero e sexualidade dentro de uma perspectiva teórica queer e com olhar direcionado a estudantes com identidades não-binárias de gêneros. Nesse artigo, retomo as narrativas produzidas pelo primeiro grupo de pessoas entrevistadas na pesquisa: cinco estudantes com identificação não-binária para o gênero ${ }^{\text {ii }}$. Para essas entrevistas foram pensados roteiros semiestruturados com questões que permeavam suas identificações, aproximações com a Teoria Queer, experiências na escola e, principalmente, com o Ensino de Biologia. De acordo com Márcia Fraser e Sônia Godim,

esta abordagem [de entrevistas semiestruturadas] almeja compreender uma realidade particular e assume um forte compromisso com a transformação social, por meio da autorreflexão e da ação emancipatória que pretende desencadear nos próprios participantes da pesquisa. (FRASER e GONDIM 2004, p. 145).

Pela metodologia escolhida, foi possível que o trabalho adquirisse outras nuances, como foi o caso de estudantes que relataram forte envolvimento com movimentações discentes relatos que aprofundo nesse trabalho. Pensar as narrativas como possibilidades para de análise é corrente nas pesquisas em Educação, principalmente por possibilitar um contato direto com os sujeitos envolvidos nas questões que se pretende estudar. Todas as entrevistas foram realizadas individualmente durante o ano de 2015 e registradas em áudio, transcrito integralmente. Os roteiros construídos direcionavam as entrevistas para os objetivos iniciais da pesquisa, entretanto, pela sua flexibilidade, não as limitavam. Para que os objetivos desse texto se cumpram, seleciono apenas uma narrativa produzida no âmbito dessa primeira pesquisa, do sujeito que denomino Estudante 1. À época, tal sujeito era discente de uma escola estadual na 
zona norte da cidade do Rio de Janeiro e escolho essa entrevista específica em função uma maior intensidade no envolvimento com organização de movimentações estudantis.

A roda de conversa Gênero, sexualidade e movimentação estudantil, por sua vez, foi pensada direccionalmente como atividade a ser realizada durante as ocupações discentes ocorridas nas escolas públicas do estado do Rio de Janeiro no inicio do ano de 2016. Seu objetivo principal foi suscitar uma discussão acerca das diferenças sexuais e de gênero dentro dos espaços de movimentos estudantis, bem como as relações afetivo-sexuais que se produziam entre as/os participantes. A roda de conversa que trago nesse texto ocorreu no mês de maio de 2016 em uma escola ocupada no município de Angra dos Reis - RJ. A escolha dessa escola se deu por acreditar que as discussões ali realizadas caminham diretamente ao encontro dos objetivos desse artigo e possuem diálogo com a narrativa produzida na entrevista da pesquisa. A atividade contou com a participação de nove jovens, com identidades sexuais e de gênero diversas, que se propuseram a participar. Não tendo um caráter obrigatório dentro da ocupação, a maioria das pessoas não demonstrou interesse na participação. Essa atividade seguiu, também, um planejamento semiestruturado: o dirigente da roda de conversa fomentava questões e situações (fictícias ou não) que iam ao encontro da temática central. Essas questões e situações eram atravessadas por gênero, sexualidade, identidades, preconceito, escola e movimentos sociais estudantis. Teve uma duração em torno de 1h10min e também foi registrada em áudio. Para a identificação das participantes denominarei, nesse artigo, como Jovem 1, Jovem 2 (até nove).

A metodologia escolhida para essa atividade, roda de conversa, é tipicamente adotada por movimentos sociais e se assemelha aos grupos focais mais comumente realizados em pesquisas acadêmicas. Entretanto, algumas particularidades devem ser observadas, como indicam Adriana Moura e Maria Lima,

A roda de conversa é, no âmbito da pesquisa narrativa, uma forma de produzir dados em que o pesquisador se insere como sujeito da pesquisa pela participação na conversa e, ao mesmo tempo, produz dados para discussão. É, na verdade, um instrumento que permite a partilha de experiências e o desenvolvimento de reflexões sobre as práticas educativas dos sujeitos, em um processo mediado pela interação com os pares, através de diálogos internos e no silêncio observador e reflexivo. (MOURA e LIMA, 2014, p. 99).

Antes, entretanto, de iniciar as discussões que me proponho, cabe realizar um sucinto dimensionamento do processo de ocupações das escolas públicas estaduais no Rio de Janeiro por estudantes do Ensino Médio. “As escolas podem ser territórios livres - livres das regras sem 
sentido, livres da polícia e do Estado - é possível organizar a escola e a sociedade de outra maneira, em que todos possam decidir conjuntamente os próprios rumos" (TERRITÓRIO LIVRE, 2016). O trecho é retirado do Manifesto da escola livre, proposto pelo jornal Território Livre, e retrata adequadamente a intencionalidade das ocupações.

Como pude pensar em trabalhos anteriores (DOS REIS, 2016), esse movimento teve início em 21 de março de 2016 em uma conjuntura política que $80 \%$ das/dos docentes realizavam uma greve. As ocupações tinham por objetivo, principalmente, alcançar melhorias nas instituições e transformações no sistema de ensino. Tanto as movimentações discentes quanto as docentes emergiram, ainda, em resposta aos cortes de investimentos destinados à Educação: no estado do Rio de Janeiro o orçamento caiu de 10,7 bilhões para 7,8 bilhões de 2015 a 2016 (MARTíN, 2016). É importante ressaltar, ainda, que as ocupações não ocorreram apenas nesse estado: também em Goiás e São Paulo dezenas de escolas estavam no mesmo processo à época.

As ocupações tiveram fim no dia 21 de junho do mesmo ano, quando discentes das duas últimas escolas ocupadas (CAIC Tiradentes e Colégio Reverendo Hugh Clarence Tucker) optaram pela desocupação (BACELAR, 2016). A soma total de escola que participaram da movimentação foi cerca de 70 instituições em todo estado. A organização geral durante o movimento se realizada a partir de assembleias diárias em cada unidade, onde eram discutidas e deliberadas funções, bem como se recebiam propostas de atividade para serem aceitas ou rejeitadas. A escola que proporcionou a discussão para a construção desse texto foi a primeira ocupada da região sul do estado e não diferia dessa organização geral.

Esse artigo se organiza, a partir dessa introdução, em três partes: duas em que penso as narrativas construídas nos espaços empíricos e uma última que aponto algumas considerações finais enlaçando as temáticas abordadas ao longo do texto.

\section{2. “começando a abrir um pouco mais o olho agora” - diálogos em gênero, sexualidade e movimentos estudantis}

A entrevista com Estudante 1, como já sinalizado, ocorreu no mês de junho do ano de 2015. Durante a entrevista acerca da diversidade de gêneros iniciamos problematizando as questões de gênero e sexualidade que permeavam sua trajetória escolar e, após poucos minutos do início, a conversa se direcionou à sua participação nos movimentos discentes. A partir disso, discutimos como os movimentos estudantis em sua escola dialogavam com as questões de gênero e sexualidade e as relações com diferentes sujeitos escolares. $\mathrm{O}$ primeiro relato foi: 
Estudante 1: A maior parte que está envolvida com o grêmio é de pessoas engajadas com o movimento feminista e o grupo LGBT. Então eles têm noção, sabe?! Eles não estão falando besteira. Mas, é uma minoria assim, que é a única que está interessada em fazer as coisas. Porque a grande massa é preguiçosa. Então eles não querem fazer nada. Se tiver um evento rolando eles vão participar, mas é um colégio cheio de burocracia, cheio de defasagem. Ainda mais que é educação pública, que teve os cortes agora. As pessoas tão começando a abrir um pouco mais o olho agora, se mobilizar mais porque já estão cansados de tanta greve e tal. Mas, sobre essa questão de minoria e tal, as pessoas não são interessadas não.

Parece-me que o "não falar besteira" para tal estudante, em outras palavras, quer dizer que o posicionamento de estudantes que compõem o movimento está alinhado às discussões progressistas no campo do gênero e da sexualidade. De acordo com a própria visão de Estudante $l$ é perceptível essa aproximação: "Você tem que começar a discussão da raiz, não questiona o gênero das pessoas, mas como como o gênero é imposto" (Estudante 1). Nesse sentido, os estudos de Rita Segato (1998, p. 8) e Judith Butler (2003, p. 8) podem nos dizer também desse discurso, uma vez que tal estudante percebe o gênero dentro de um sistema de imposição. Nas palavras das autoras: a matriz heteronormativa, ou seja

a matriz primigênia do poder, o primeiro registro ou inscrição do poder na experiência social e na vida do sujeito. Qualquer um que seja o conjunto de traços que venham a preencher a imagem do feminino e do masculino em cada cultura particular, a estrutura básica do masculino como sujeito falante, que entra ativamente no âmbito público das trocas de signos e objetos, e de um feminino/objeto/signo permanece no cerne das relações de gênero.

Podemos, então, entender essa matriz como base para o estabelecimento do poder e da naturalização dos corpos, gêneros e desejos - dentro e fora da escola, dentro e fora dos movimentos sociais. Como primeira inserção do poder na socialização do sujeito, pode ser apresentada como uma grade de símbolos culturais e sociais que se estabelecem de forma cognitiva. Nela, todos os sujeitos são imersos numa repetição ordenada de signos que começa com o que a mesma autora define como primeira cena: aquela em que o indivíduo é exposto e continua através de um emaranhado de fatores (como mídia e escolarização) se orientando e classificando os sujeitos de acordo com um ideal comportamental. Esse ideal nunca será plenamente alcançado, mas aquela ou aquele que não fizer a tentativa ou desviar da performance de representação do papel pagará com sua dignidade e estará exposta ou exposto às violências de todo tipo, desde olhares enviesados até linchamentos fatais. 
Também é interessante pensar que, nessa escola, estudantes do grêmio estudantil estão relacionados aos movimentos de identidades marginalizadas. Penso com Maria Heilborn (2002, p. 78) que os diferentes espaços sociais que as pessoas se inserem serão fundamentais para sua constituição como sujeitos e influenciadores na forma com a qual estes enxergam o entorno e a si próprios. Assim, a partir da inserção e diálogo com diferentes espaços de representação e movimentação, tais estudantes podem se constituir como sujeitos políticos que tragam a diferença como pauta principal para pensar as transformações.

Continuando a explorar a questão do movimento estudantil dentro de sua escola, Estudante 1 direcionou a conversa para a relação por vezes conflituosa que se estabelece entre as instâncias administrativas escolares com os movimentos. No relato, é exposto:

Estudante 1: A gente tem um apoio lá. A gente dialoga pra marcar as coisas e aí eles ajudam. Tudo bem, se vocês conversarem. Apesar de agora ter mudado a coordenação, ela ficou meio, um pouco mais barrando as coisas. Eu achei até engraçado que ela foi tão autoritária que a gente não falou nada.

O caso de acima, retratado como autoritarismo, aconteceu diante de um evento realizado pela Frente Negra da escola - movimentação estudantil que visa fomentar as discussões de raça e etnia. O grupo, ligado ao Grêmio Estudantil e em comunhão com outros grupos organizados (como o feminista e LGBTTI ${ }^{\mathrm{iii}}$ ), criou um evento na rede social Facebook onde aconteceram os convites entre os membros do corpo estudantil e profissional da escola para um sarau. Entretanto, o evento não foi comunicado anteriormente à gestão da escola, que os convocou para uma conversa.

Estudante 1: Então a direção chamou a gente e falou "O que vocês estão fazendo? Vocês não comunicaram o que vocês vão fazer lá." E aí eu não me lembro o que estava escrito na descrição, mas era tipo assim: "Ah, não vão amarrar nossa cultura negra” tipo assim, "nós vamos ter um espaço” e tal.

O evento ocorreu, de qualquer forma, apesar da conversa com a gestão. Entretanto, algumas reverberações se produziram em estudantes que se envolveram. A provocação me parece ser palavra-chave para pensar a movimentação desse grupo de estudantes na escola, como prossegue o relato:

Estudante 1: E a diretora branca lá falando que aquilo deu um mal estar nela, de ter lido uma parte. Dai eu fiquei tipo "que bom cara, foda-se que você ficou incomodada". Sabe, é pra incomodar mesmo, pra eles terem espaço. E ela não deu espaço pra que a gente falasse, 


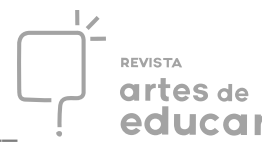

falou que incomodou e tipo assim "podem ir". Tem coisas que eles ainda acham que é exagero. Só por a gente estar ocupando os espaços. Então eu vejo isso lá dentro, bastante.

A partir da situação experienciada, entendo os movimentos estudantis de identidades marginalizadas, entre eles o LGBTTI, já como uma ocupação de espaços geralmente negados. O que a escrita de Rita Radl-Philipp (2014, p. 52) vai entender como um rompimento do silenciamento promulgado pela cultura escolar, uma pista do papel transformador de estudantes nessa dinâmica. Não me parece ser justo entender esses indivíduos como sujeitos passivos que apenas incorporam conceitos rígidos e pré-estabelecidos na escola. Eles, ao contrário, constituem a socialização escolar ativamente, interferindo na sua dinâmica e dando formatos novos e característicos naquela geração através da provocação, do embate, da desestabilização. As atividades desenvolvidas por eles poderão manter padrões antigos sem o questionamento de relações de poder, por exemplo, ou assumir novos significados e significantes. No que concerne ao gênero, as alunas e os alunos reproduzem o esquema binário, mas também podem completá-lo ou ressignificá-lo - como é o caso de Estudante 1. Lorenzo Bernini (2011, p. 20) explora essa ressignificação apontando que gêneros e sexualidades marginalizados têm forçado a entrada no sistema educacional, rompendo - ou, ao menos, desestabilizando - com os binarismos. Essas ações abalam o sistema repressivo que impõe uma matriz heteronormativa.

Ainda que, num plano geral da escola, os movimentos estudantis parecem compreender apenas uma minoria de estudantes, eles são encarados como espaços de encontro e acolhimento das diferenças. De acordo com Estudante 1, foi em função dessa aproximação com os movimentos que o colégio passou a ser encarado com outros olhos. Ainda que nem todo movimento tenha ligação com identidades não-binárias de gênero, a maior parte é envolvida com correntes do feminismo e causas LGBTTI.

A entrevista com Estudante 1 ocorreu alguns meses antes do início dos movimentos de ocupações no estado, em um momento que os cortes de investimentos na Educação já estavam avançando e "começando a abrir um pouco mais o olho agora, se mobilizar mais". As juventudes que já estavam mobilizadas nos grêmios e outros movimentos identitários atuam de forma a, como aponta Alberto Melucci, antecipar a "utopia, anunciando hoje, e de forma profética, uma outra possibilidade da vida em conjunto" (MELUCCI, 1997, p. 87, grifos do autor).

\section{3. "apesar de tudo nós estamos aqui pra fazer a diferença"-ocupar e (re)existir na diferença}

A roda de conversa Gênero, sexualidade e movimentação estudantil ocorreu um mês após o início do movimento de ocupação, tendo sido proposta a partir de um diálogo informal com um 
dos jovens ocupantes. Apresentarei os diálogos na ordem que ocorreram, a partir das temáticas que foram sendo discutidas. Logo que cheguei à escola ocupada fui questionado sobre o nome da atividade que iria realizar naquela tarde, quando respondi com o título, o grupo se manifestou: “entendemos, é aquilo que fala de veado e sapatão né?!'. Após dessa fala iniciamos a atividade com um momento de apresentações pessoais após as quais se deu o questionamento:

Pesquisador: Dentro da escola, o que vocês discutem de gênero e sexualidade?

Jovem 2: Nada.

Jovem 6: A gente teve uma aula aqui.

Jovem 3: A gente teve uma aula com a professora Renata ${ }^{i v}$ na ocupação. Agora fora da ocupação não teve. Nunca teve.

Pesquisador: E fora da escola, onde vocês discutem ou ouvem falar de gênero e sexualidade?

Jovem 6: Televisão.

Jovem 2: Internet.

Jovem 6: Oh, bota internet nisso!

Jovem 2: Tem gente cagando sobre o assunto, mas enfim... internet.

Como observado, as discussões produzidas no âmbito da roda de conversa que trago nesse texto não foram as primeiras realizadas sobre gênero e sexualidade naquela ocupação, entretanto foi a primeira que visava relacionar o papel daquela movimentação nesses debates. Antes disso, entretanto, é importante notar que tais estudantes não identificam na escola uma discussão que permeie os temas em questão. Com o diálogo podemos inferir que a transversalização da Orientação Sexual proposta pelos Parâmetros Curriculares Nacionais não parece ocorrer no processo educativo nos casos estudados - reforçando os apontamentos de Cassiane Diniz (2014), Adriano Senkevics (2012) e Guacira Lopes Louro (2000). Ou seja, parece existir uma carência sistêmica para tratar da temática.

Entretanto, acredito que o sentido produzido por tais estudantes é que essas temáticas não são discutidas dentro de um currículo formal na perspectiva da diversidade ou da diferença; pois, quando a escola se limita a trabalhar questões apenas de cunho "biológico" - conceito que é questionado por Anne Fauto-Sterling (2006, p. 45) - e não discutir a diversidade/diferença, ela está realizando um trabalho de gênero e sexualidade, mas um trabalho que silencia os corpos (e identidades) que a Ciência Moderna não previu ou tratou enquanto patologias. Relações, conceitos, delimitações e discussões presentes em uma aula de Biologia, por exemplo, poderão ter efeitos variados: desde o silenciamento de estudantes que irão divergir de um suposto binário 
natural até o diálogo verdadeiro numa tentativa de inclusão das diversas realidades à dinâmica escolar, de maneira a repensar algumas verdades estabelecidas nas ciências.

Nesse sentido, de compreender que gênero e sexualidade são trabalhados na escola - e para fora dela -, foi proposto na roda de conversa um questionamento sobre o que as pessoas participantes entendiam por gênero e por sexualidade.

Jovem 1: O que a pessoa é: homem, mulher, gay, sapatão, lésbicas. E gênero é o que nasceu? Se nasceu masculino e virou gay.

Jovem 2: Eu acho que sexualidade é como você se relaciona com o próximo. Gênero é como você se identifica. Eu acho que é isso, posso estar errado.

Jovem 3: Eu também concordo.

Jovem 4: Concordo.

O saber discente produzido será marcado, muitas vezes, a partir do foco de trabalho de determinada questão nas salas de aula. A confusão entre o que é sexualidade, gênero ou sexo biológico se mostra latente, por fim levando a uma produção de sentido que nem sempre ocorre no cotidiano escolar. O discurso de Jovem 2 se aproxima do campo de estudos ao afirmar o caráter relacional da sexualidade e o caráter identitário do gênero. Compreendendo que a sexualidade funciona como um dispositivo, isto é,

um conjunto decididamente heterogêneo que engloba discursos, instituições, organizações arquitetônicas, decisões regulamentares, leis, medidas administrativas, enunciados científicos, proposições filosóficas, morais, filantrópicas. Em suma, o dito e o não dito são os elementos do dispositivo. O dispositivo é a rede que se pode estabelecer entre estes elementos. (FOUCAULT, 1980, p. 244)

Então, os sujeitos se estabelecem em posicionamentos, funções e metodologias, num tipo de jogo - o caráter relacional. Mais que um ato inicial de estímulo ou de repressão, a sociedade se torna peça essencial, histórica e culturalmente localizada, que dará direções aos percursos sexuais - neles contido o desejo - e elabora os seus significados.

O caráter identitário se caracteriza na concepção individual de sou homem, sou mulher ou sou um gênero a parte dessas opções; enquanto que a expressão de gênero pode ser encarada como a representação física - incorporada - dessa identificação. Judith Butler (2003, p. 12) nos amplia esse caráter para uma complexidade apontando que o "conceito de gênero exige um conjunto interdisciplinar e pós-disciplinar de discursos, com vistas a resistir à domesticação acadêmica dos estudos sobre gênero ou dos estudos sobre as mulheres”. Assim, após discussões, 
exemplificações e relatos de artefatos culturais, as palavras produziram novos sentidos para os sujeitos participantes da roda de conversa.

Pesquisador: E então depois de tudo que vocês pensaram, qual a diferença entre gênero, sexualidade e sexo biológico?

Jovem 3: Sexo biológico é o que a gente nasce. Genético.

Jovem 2: Vocês viram na TV aquele caso de um casal que engravidou? Um homem e uma mulher. Só que o homem se identificava como mulher e a mulher se identificava como homem. Eles tiveram um filho. As pessoas acharam aquilo uma mega aberração.

Jovem 3: Gênero eu acho que é isso né? Identificação.

Jovem 7: Orientação sexual sabemos o que é.

Jovem 2: Jovem 1 você é gay.

Jovem 1: Não, pego os dois. Tanto que eu namoro uma menina.

Jovem 2: Vc é bi?

Jovem 3: E como você se veste? Se veste como homem ou como mulher?

Jovem 1: Me visto como homem e como mulher. Mentira, só como homem.

Jovem 3: Então você é a mesma coisa que eu: viado-hétero. É uma identificação como bi.

O sentido sexo biológico escolhido pelos sujeitos (dentre hormonal, urogenital, psíquico etc), foi o genético. Anne Fausto-Sterling indica que esse sentido é o mais recente nas aproximações do campo das Ciências Naturais com as temáticas de gênero e sexualidade (FAUTO-STERLING 2006, p. 40). Outros sentidos, entretanto, são produzidos e novas palavras acionadas, como é o caso de identificação de Jovem 3: viado-hetero. Como exposto em trabalho anterior (DOS REIS, 2016), o termo proposto ressignifica as palavras, desestabilizando a rigidez dos conceitos de gênero e sexualidade.

E, não pela primeira vez durante a atividade, casos reais de propagação nos artefatos culturais chegam à discussão e movimentam a escola, como o citado de um casal de pessoas transgêneros que tiveram um filho. Como aponta Ruth Sabat (2001, p. 16), o que ela chama de currículo cultural (esse conjunto de reforços constituídos e constituidores de relações sociais) "faz parte de uma pedagogia específica, composta por um repertório de significados que, por sua vez, constroem e constituem identidades culturais hegemônicas”. Esse currículo gera influência, por vezes até maiores, na constituição do enxergar o mundo e do enxergar-se. A mídia é um dos fatores mais marcantes do milênio e diversos estudos (SCORALICK, 2009; FERREIRA e CAMARGO, 2001; PEREIRA, 2008; QUEIROZ, 2005) apontam-na como forte responsável 
pela formação de (pre)conceitos ou resistência a eles. Sobre a representação de sexualidades marginalizadas, Jandira Queiroz afirma que a mídia brasileira

\begin{abstract}
é uma importante fonte de informação sobre o mundo para muitas pessoas, imagens equivocadas ou pouco realistas das minorias sexuais têm um efeito nocivo, já que promovem uma ilusão de que estas pessoas não experienciam alegrias, problemas cotidianos ou emoções humanas. Muitas vezes os jovens brasileiros (e adultos também) se espelham em personagens de novelas e a partir disso orientam suas ações. Neste sentido, podemos dizer que as telenovelas são uma ferramenta importante na afirmação de identidades heterossexuais. (QUEIROZ, 2005, p. 51)
\end{abstract}

Para concluir a atividade da roda de conversa, coube refletir como todos esses conceitos, informações e relações se estabeleciam dentro do âmbito daquela ocupação:

Pesquisador: E agora é pensar, a partir disso, esse movimento de respeito, esse movimento de não-preconceito, de não-discriminação dentro da ocupação de vocês.

Jovem 3: Seria bom se todos estivessem aqui, mas...

Jovem 2: Mas o interessante aqui na ocupação é que, independente dessas piadas que existem, todo mundo se respeita muito. Assim, num primeiro contato eu achei que ia dar problema, em função de gente homofóbica, que eu vi pessoas.

Jovem 7: Mas, de verdade, já me chamaram de muitas coisas aqui.

Jovem 2: Mas aí você vê uma coisa aqui: os garotos de cumprimentando, que é uma coisa simples, dar um abraço. Todo mundo muito carinhoso. Independente se é mulher com mulher, homem com homem. Então eu acho que a ocupação deu uma baixada nisso, o pessoal ta bem tranquilo quanto a isso.

Jovem 3: É que apesar de tudo nós estamos aqui pra fazer a diferença.

Como sinaliza Jovem 3, nem todas as pessoas estavam presentes. Isso ocorreu, perceptivelmente, em função da temática a ser discutida na roda de conversa. Salvo duas pessoas, todas as outras que participavam se enquadram dentro da população LGBTTI. Enquanto que nenhuma das pessoas ausentes se identificava como membro do mesmo grupo. Assim como o caso de Estudante 1 - exposto na sessão anterior - acredito que a discussão de gênero e sexualidade dentro daquele movimento de ocupação se configurou como um espaço de resistência e de possibilidade de expor angústia, anseios, dúvidas e alegrias.

Mesmo com a ausência das/dos demais integrantes da ocupação, as pessoas que se fizeram presentes puderam reconhecer que a ocupação "deu uma baixada nisso”. Em outras palavras, os casos de preconceito e discriminação que permeavam o ambiente escolar parecem ter sido 
reduzidos em função da constituição de um movimento estudantil. Essa característica rizomática de transformação proporcionadas pelos movimentos é exemplificada por Denise Araújo,

o caminhar dos movimentos sociais em suas conquistas, as mudanças na expressão da arte, a valorização e projeção de pessoas reconhecidamente fora da norma, a autoidentificação de pessoas da mídia, a maior visibilidade de discussões sobre banheiros separados por sexo, os nomes sociais, o casamento civil e a adoção de crianças por casais do mesmo sexo, entre outras coisas que certamente surgirão, serão capazes de abalar as estruturas da sociedade heteronormativa. (ARAÚJO, 2014, p. 08)

Como também apontou Cláudia Vianna (2015, p.13) ressaltando a importância de movimentos sociais para ampliação de discussões que antes eram incentivadas apenas nos ambientes das Universidades, acredito que os movimentos de ocupação possibilitaram uma discussão não apenas relacionadas às melhorias orçamentárias e estruturais na Educação Básica, mas também uma compreensão da diferença como fator constituinte da escola, que deve ser valorizado e compreendido como gerador de novos sentidos e possibilidades.

\section{Considerações finais}

Como indica Altemir de Oliveira, "as escolas necessitam de novas propostas pedagógicas, para diminuir o hiato produzido pelas oposições binárias, assim, contemplando as pessoas que foram, historicamente, excluídas em nossa sociedade" (OLIVEIRA, 2011: 31). Nesse sentido, acredito que as organização e movimentações discentes têm grande potencialidade em incorporar à dinâmica escolar práticas de desestabilização e transformação das hierarquias, bem como em socializar as pessoas (estudantes ou não) que passam pelos processos - pensando, ainda, em todos os atravessamentos que poderão significar produção de novos sentidos, experiências e identidades.

Concernente às temáticas de gênero e sexualidade, percebo, aliado às discussões que se produzem nas pesquisas em Educação - como a de Felipe Bastos (2015) - que suas entradas na sala de aula (e escola como um todo) são realizadas, muitas vezes, por via discente: dúvidas, conexões com conteúdos do currículo formal, provocações, afetos e, até mesmo, brincadeiras. Estudantes trarão (e comporão) cotidianamente suas experiências afetivo-sexuais para dentro do espaço escolar, oportunizando uma criticidade tanto por docentes quanto por elas/eles mesmas/mesmos. 
Nas duas formas de movimentação estudantil apresentadas nesse artigo é observado que essa entrada, entretanto, pode ser realizada de forma organizada. Um planejamento que ultrapasse as demandas surgidas na experiência. Algo que desestabiliza não apenas as normas da matriz de gênero e sexualidade, mas, ainda, o próprio binário que se produz na escola: do docente que ensina, planeja e detém os conhecimentos e oposição ao discente que aprende, absorve saberes.

\section{Referências Bibliográficas}

ARAÚJO, Denise. Outras falas sobre gênero e sexualidade na escola. Revista Periódicus. Salvador, v. 1, n. 2, p. 19-27, 2014.

BACELAR, Daniele. Ocupação nas escolas chega ao fim. O Dia. Disponível em: <http://odia.ig.com.br/rio-de-janeiro/2016-06-21/ocupacao-nas-escolas-chega-ao-fim.html> Acesso em 28 de agosto de 2016.

BASTOS, Felipe. "A diretora sabe que você está trabalhando isso na sala de aula?": Diversidade sexual e ensino de ciências. Dissertação. 180p. Pontifícia Universidade Católica do Rio de Janeiro, Departamento de Educação. 2015.

BERNINI, Lorenzo. Macho e fêmea Deus os criou!? A sabotagem transmodernista do sistema binário sexual. Bagoas - Estudos gays: gêneros e sexualidades. Natal. v. 5, n. 06, 2012. ISSN 2316-6185.

BUTLER, Judith. Problemas de gênero: feminismo e subversão da identidade. 236p. Rio de Janeiro: Editora Record, 2003.

DINIZ, Cassiane. Quem inventou o sexo? Experiências cotidianas de crianças e professoras acerca de gênero e sexualidade. 2014. Dissertação (Programa de Pós-Graduação em Antropologia Social). Universidade de Brasília, Brasília.

DOS REIS, Neilton. Diversidade de gêneros e Ensino de Biologia: casos de prazeres e corporeidade não-binários. Monografia. 105p. Universidade Federal Rural do Rio de Janeiro, Curso de Licenciatura em Ciências Biológicas. 2015.

DOS REIS, Neilton. Movimentação estudantil: identidades sexuais e de gênero em trânsito. Revista Mosaico. Rio de Janeiro. v. 7, n. 11. 2016

FRASER, Márcia.; GONDIM, Sônia. Da fala do outro ao texto negociado: discussões sobre a entrevista na pesquisa qualitativa. Paidéia. Ribeirão Preto; v. 14, n. 28, p. 139-152, 2004. ISSN 0103-863X.

FAUSTO-STERLING, Anne. Cuerpos sexuados: la política de género y la construcción de la sexualidad. Barcelona: Melusina. 526p. 2006.

FERREIRA, Ricardo; CAMARGO, Amilton. A naturalização do preconceito na formação da identidade do afro-descendente. EccoS Revista Científica. São Paulo. vol. 3, núm. 1, junho, 2001, pp. 75-92

FOUCAULT, Michel. História da sexualidade I: a vontade de saber. 152p. 3 ed. Rio de Janeiro: Graal, 1980. ISBN 8570380100.

HEILBORN, Maria. Fronteiras simbólicas: gênero, corpo e sexualidade. Cadernos Cepia. Rio de Janeiro.v. 5, p. 73-92, 2002. 
LOURO, Guacira. O corpo educado: Pedagogias da sexualidade. Traduções: Tomaz Tadeu da Silva. $2^{a}$ ed. 127p. Belo Horizonte: Autêntica, 2000.

MOURA, Adriana Ferro; LIMA, Maria Glória. A Reinvenção da Roda: Roda de Conversa, um instrumento metodológico possível. Revista Temas em Educação, v. 23, n. 1, p. 95-103, 2014.

MARTÍN, María. Escolas ocupadas já são 65 no Rio e Estado enfrenta impasse na negociação. El

País.

Disponível

em:

<http://brasil.elpais.com/brasil/2016/04/29/politica/1461955632_442061.html> Acesso em 04 de julho de 2016.

MELUCCI, Alberto. Juventude, tempo e movimentos sociais. Revista Brasileira de Educação. São Paulo v. 5, n. 6, p. 5-14, 1997.

PEREIRA, Pedro. Body, sex and subversion: reflections on two queer theoreticians. Interface Comunicação, Saúde, Educação, v.12, n.26, p.499-512, 2008.

QUEIROZ, Jandira. Rumo ao final do arco-iris: $O$ que mudou no discurso sobre personagens homossexuais na grande midia de entretenimento na ultima decada e por que? 66p. 2005. Trabalho de Conclusão de Curso. Centro Universitário de Brasília.

RADL-PHILIPP, Rita. Educación y socialización humana, identidades y nuevos roles de género femenino y masculino: el género a debate. Em Aberto. Brasília.,v. 27, n. 92, p. 1-212, 2014.

SABAT, Ruth. Pedagogia cultural, gênero e sexualidade. Estudos Feministas. Santa Catarina. n. 09. 2001.

SCORALICK, Kelly. Mídia, cidadania, informação e direito à comunicação: a identidade dos deficientes nos telejornais. IN: Congresso de Ciências da Comunicação na Região Sudeste. UFRJ. Rio de Janeiro. 2009.

SEGATO, Rita. Os percursos do gênero na antropologia e para além dela. Série Antropologia. 22p. Brasília: Departamento de Antropologia, Universidade de Brasília, 1998.

SENKEVICS, Adriano; POLIDORO, Juliano. Corpo, gênero e ciência: na interface entre biologia e sociedade. Revista da Biologia. São Paulo. v. 9, n. 1, p. 16-21, 2012.

TERRITÓRIO LIVRE. Manifesto Da Escola Paralela. Disponível em <http://territoriolivre.org/manifestoescolaparalela/> Acesso em: 04 de julho de 2016.

VIANNA, Cláudia. O movimento LGBT e as políticas de educação de gênero e diversidade sexual: perdas, ganhos e desafios. Educação \& Pesquisa. São Paulo. p. 1-16, 2015.

\footnotetext{
' Neilton dos Reis. Mestrando em Educação pela UFJF. Rua Lourenço Kelmer, S/N, São Pedro, Juiz de Fora, MG, 36036-900.neilton.dreis@gmail.com

${ }^{\text {ii }}$ Refere-se a pessoas que não contemplam sua identidade de gênero como $100 \%$ masculina ou $100 \%$ feminina, mas permeiam por elas, fixando-se ou não em identidades entre esses polos ou para além dessa linha.

iii Elegi a sigla LGBTTI para indicar grupos de Lésbicas, Gays, Bissexuais, Travestis, Transexuais e Intersexuais. Entendo que existam muitas combinações desses termos no esforço de representar as diferenças sexuais e de gênero. No entanto, acredito que nenhuma combinação dê conta da diversidade de identidades (e diferenças) que habitam esses grupos.

iv Nome fictício escolhidos pelo autor.
} 